\title{
Bee responses to landscape composition on coupled and decoupled multiscale approaches
}

Lazaro Carneiro ( $\nabla$ lazarocarneiro16@gmail.com )

Universidade Estadual do Norte Fluminense: Universidade Estadual do Norte Fluminense Darcy Ribeiro https://orcid.org/0000-0001-7807-3099

\section{Milton Cezar Ribeiro}

UNESP: Universidade Estadual Paulista Julio de Mesquita Filho

Willian Moura de Aguiar

UEFS: Universidade Estadual de Feira de Santana

Camila de Fátima Priante

UENF: Universidade Estadual do Norte Fluminense Darcy Ribeiro

Wilson Frantine-Silva

UENF: Universidade Estadual do Norte Fluminense Darcy Ribeiro

Maria Cristina Gaglianone

UENF: Universidade Estadual do Norte Fluminense Darcy Ribeiro

\section{Research Article}

Keywords: landscape structure, spatial heterogeneity, forest cover, scale of effect, pollinator

Posted Date: August 20th, 2021

DOl: https://doi.org/10.21203/rs.3.rs-750143/v1

License: (c) (i) This work is licensed under a Creative Commons Attribution 4.0 International License.

Read Full License

Version of Record: A version of this preprint was published at Landscape Ecology on April 15th, 2022. See the published version at https://doi.org/10.1007/s10980-022-01442-8. 
3 Lázaro da Silva Carneiro ${ }^{1}$, Milton Cezar Ribeiro², Willian Moura de Aguiar $^{3}$, Camila de Fátima

4 Priante $^{1}$, Wilson Frantine-Silva ${ }^{1}$, Maria Cristina Gaglianone ${ }^{1}$

$5{ }^{1}$ Centro de Biociências e Biotecnologia, Laboratório de Ciências Ambientais, Universidade

6 Estadual do Norte Fluminense- UENF, Av. Alberto Lamego, 2000 - Parque Califórnia, Campos

7 dos Goytacazes, RJ, CEP 28013-602, Brazil,

8 2Departamento de Biodiversidade, Instituto de Biociências, Universidade Estadual Paulista-

9 UNESP, Av. 24 A, 1515 - Bela Vista, Rio Claro, SP, CEP 13506-752, Brazil

10 32Departamento de Ciências Biológicas, Universidade Estadual de Feira de Santana- UEFS, Av.

11 Transnordestina, s/n, Novo Horizonte, Feira de Santana, BA, CEP 44036-900, Brazil

12 Corresponding author: LS Carneiro, e-mail: lazarocarneiro16@gmail.com, Tel. Number:

$13+5522998336528$

14 LS Carneiro ORCID: 0000-0001-7807-3099

15 MC Ribeiro ORCID: 0000-0002-4312-202X

16 WM Aguiar ORCID: 0000-0002-2825-8623

17 CF Priante ORCID: 0000-0003-2543-1985

18 WS Frantine ORCID: 0000-0002-4293-0471

19 MC Gaglianone ORCID: 0000-0002-9206-2895

21 Abstract

22 Context

23 Multiscale approaches are essential for understanding ecological processes and detecting the scale

24 of effect. However, nested multiscale approaches retain the effect of the landscape attributes from 25 the smaller spatial scales into the larger ones. Thus, decoupling local vs. regional scales can reveal 26 detailed ecological responses to landscape context, but this multiscale approach is poorly explored.

27 Objectives

28 We evaluated the scale of effect of the forest cover (\%) and landscape heterogeneity on Euglossini

29 bees combining coupled and decoupled multiscale approaches.

30 Methods

31 The Euglossini males were sampled in forest patches from 15 landscapes within the Atlantic 32 Forest biodiversity hotspot, southeast Brazil. For simplicity, we defined that the coupled 33 approaches represented the local scales and decoupled approaches the regional scales. We 
35 decoupled the scales by cutting out the smaller scales inserted into larger ones. We estimated the

36 relationship of the bee community attributes with forest cover (\%) and landscape heterogeneity in

37 local and regional scales using Generalized Linear Models.

38 Results

39 We found positive effects of landscape heterogeneity on species richness for regional scales.

40 Forest cover (\%) and landscape heterogeneity in local scales showed positive effects on the

41 euglossine abundances. The scale of effect for euglossine richness was higher than species 42 abundances.

\section{Conclusions}

44 Combining coupled and decoupled multiscale approaches showed adequate capture of the scale of effect of the landscape composition on bee communities. Therefore, it is of paramount importance to measure the influence of the landscape context on biodiversity. Maintaining landscapes with

47 larger forest cover and spatial heterogeneity is essential to keep euglossine species requirements.

48 Keywords: landscape structure, spatial heterogeneity, forest cover, scale of effect, pollinator

\section{Acknowledgments}

60 We are grateful to the Bee and Pollination Lab team (UENF) for their help in the field; the owners

61 for authorizing sampling on their properties; Dr. Gabriel Augusto Rodrigues de Melo (UFPR) for 62 taxonomic confirmation; Instituto Brasileiro do Meio Ambiente e dos Recursos Naturais 63 Renováveis- IBAMA for the permission to collected biological material; and the Conselho 64 Nacional de Desenvolvimento Científico e Tecnológico - CNPq, Ministério da Ciência, 65 Tecnologia, Inovações e Comunicações - MCTIC, IBAMA, Associação Brasileira de Estudo das 66 Abelhas - A.B.E.L.H.A. for project financing (CNPq/MCTIC/IBAMA/A.B.E.L.H.A. 67 400614/2018-9). 


\section{Introduction}

One of the main goals in Ecology is to establish relationships between patterns (e.g. spatial heterogeneity) and processes (e.g. pollination) at different spatio-temporal scales (Turner 1989; $\mathrm{Wu}$ 2007; Turner and Gardner 2015). The use of multiscale approaches is essential since ecological systems are hierarchically structured in different levels of space and time (Allen and Starr 1982; Wiens 1989; Levin 1992; Jackson and Fahrig 2015). Nonetheless, the use of incorrect scales for landscape analysis, for example, can result in flaws or observations of spurious relationships between these patterns and processes, even when they exist (Cushman and Landguth 2010; Jackson and Fahrig 2015).

The ecological responses to spatial heterogeneity patterns have been influenced by changes in the habitat and the landscape structure, often driven by habitat loss and fragmentation processes (Haddad et al. 2015; Püttker et al. 2020). This process modifies the landscape structure by increasing the edge effect, patch number, and spatial isolation, as well as by reducing habitat patch and functional connectivity (Kupfer et al. 2006; Fahrig 2017). Landscape disturbances and spatial heterogeneity interact in different ways, influencing ecological processes in different spatiotemporal scales (O'Neill et al. 1996; Wu 2004; Newman et al. 2019). Therefore, it is expected that the relationship between biodiversity and landscape parameters will be stronger at a specific spatial scale, i.e. the scale of effect (Milne 1991; Holland et al. 2004; Miguet et al. 2016). Individuals and species within populations and communities can perceive and respond to the environment differently, resulting in different scales of effect (Boscolo and Metzger 2009; Miguet et al. 2016; Amiot et al. 2021). The scales of effect of landscape attributes on biological responses are generally unknown (Miguet et al. 2016; Martin 2018). The criteria of which spatial scales will be used are often based on the researcher's perception of the species features, such as dispersal distance and home range (Jackson and Fahrig 2012; Amiot et al. 2021). However, studies have generally sub-optimized the accurate detection of the scale of effect because they use one or a few spatial scales or these scales are larger or smaller than the true scale of effect (Jackson and Fahrig 2015; Miguet et al. 2016). Determining the scale of effect is challenging for ecologists and conservationists, and at the same time, it is crucial for understanding how natural processes and human pressures interact in space-time.

Multiscale approaches have been used to detect the scale of effect of landscape structure on biological attributes or ecological responses related to different taxonomic groups, such as terrestrial mammals (Lyra-Jorge et al. 2010; Nagy-Reis et al. 2017; Amiot et al. 2021), primates 
101

(Nagy-Reis et al. 2017; Gestisch et al. 2018), plants (Collevatti et al. 2020 ), birds (Boscolo and Metzger et al. 2009; Morante-Filho et al. 2016) and insects (Steffan-Dewenter 2002; Rossi \& van Halder 2010; Franceschinelli et al. 2017). Most of these studies were developed using a focal patch design (Brennan et al. 2002; Miguet et al. 2016), wherein the quantification of the landscape structure occurs in each of the landscapes nested in different sizes (e.g. 500, 1000, $1500 \mathrm{~m}$ ). There are changes in spatial heterogeneity attributes with the increase in the spatial scales (i.e. landscape size) because new elements are added to the system (Allen and Hoekstra 1991; Milne 1991; Turner and Gardner 2015). Although the evaluation of larger scales (nesting the smaller ones) might detect the influence of the new elements on the patterns and ecological processes, those effects might also be inherently correlated to those observed in the smaller spatial scales, which is very common on nested landscape quantifications within various buffer sizes (Allen and Starr 1982; Wu 2004; Gestich et al. 2018; Collevatti et al. 2020). Thus, even if a certain scale of effect of an explanatory variable on an ecological response one would be the largest spatial extension evaluated, it is expected that there will also be detected influences from the adjacent smaller scales or buffer sizes (Rhodes et al. 2009). Although the current trend is to use a nested multiscale approach (i.e. various buffers surrounding the sample point varying buffer sizes), here we proposed to use a combination of both coupled (i.e. nested scales) and decoupled (i.e. local vs. regional) multiscale approaches to evaluate the best scale of effect of the forest cover and the landscape heterogeneity on Euglossini bees communities. With this, we call attention to the importance of decoupling local and regional scales of effect on exploring different taxonomic groups or ecological processes within human-dominated landscapes.

The Euglossini bees are essential pollinators in the neotropical forests, associated with more than 40 botanical families and hundreds of orchid species exclusively pollinated by euglossine males (Dressler 1982; Roubik and Hanson 2004). Most of these bee species depend on the forest for nesting sites and floral resources (Roubik and Hanson 2004), which the individuals can access using their astonishing flight capacity to explore large continuous landscape areas (Wikelski et al. 2010; Pokorny et al. 2015). Because of this, euglossine bees are important bioindicators for assessing the effects of forest cover loss and landscape degradation at different spatial scales. These processes can negatively affect the euglossine abundance and gene flow (Freiria et al. 2012; Cândido et al. 2018; Frantine-Silva et al. 2021), but may also respond positively to increased compositional heterogeneity (Opedal et al. 2020; Carneiro et al. 2021). Indeed, these results and others elsewhere (e.g. Aguiar et al. 2015; Cândido et al. 2018; Allen et al. 2019) indicate the importance of the landscape context surrounding forest patches on the 
euglossine communities. However, specific responses to different spatial scales and the scale of effect are still allusive, highlighting the importance of assessing these bee communities in multiscale approaches.

The main objective of this investigation was to evaluate the scale of effect of the landscape composition on Euglossini community attributes (richness, total abundance, and abundance of common, intermediate, and rare species). We quantified the forest cover (\%) and landscape heterogeneity through multiscale approaches exploring a combination of two multiscale approaches: coupled and decoupled scales. Before we present our expectations on our focal taxonomic group, it is important to emphasize that we advocate that researchers worldwide would adapt our proposal to any ecosystem, taxa, or ecological processes, just adapting what can be considered local, regional (or even macroregional) levels. In the scope of this study, we defined that the coupled multiscale approach represents the local landscape composition, and the decoupled multiscale approach the regional landscape composition. Because landscape structure and ecological parameters have many interaction levels (Miguet et al. 2016; Amiot et al. 2021), we address several questions with the main hypotheses summarized in Fig. 1. Regarding the explanation of the variables, we hypothesized that forest cover and landscape heterogeneity would have more explanatory power in local and regional scales, respectively (Fig. 1a). Likewise, we hypothesized that bee abundance and richness would increase with forest cover and heterogeneity in both local and regional scales (Fig. 1b). We hypothesized positive and negative responses of each euglossine community attribute on a respective scale as described in Fig. 1c-1f. We expected the scale of effect of forest cover on the euglossine abundance to be at local scales (SteffanDewenter 2002; Brosi 2009; Miguet et al. 2016). Finally, we also expected the scale of effect of landscape heterogeneity on euglossine richness to be at regional scales (Miguet et al. 2016; Jackson and Fahrig, 2014; 2015).

\section{Material and Methods}

\subsection{Study area}

We carried out this study in 15 fragmented landscapes from Southeast Brazil, an area originally covered by the Atlantic Forest (Fig. 2). This tropical rain forest is threatened by human actions that resulted in a high fragmentation and forest cover loss (Ribeiro et al. 2009; Fundação SOS Mata Atlântica and INPE 2021). Besides forest cover, coffee crops and pastures are the main landscape covers in the region (Fig. 2). More information about the study area in Carneiro et al. (2021). 


\subsection{Euglossini bee community}

We sampled the euglossine males through five bait traps (eucalyptol, eugenol, methyl cinnamate, methyl salicylate, and vanillin) at a sampling point within a forest patch in each landscape. The minimum size of the chosen forest patches was 5 ha, and the minimum distance between the sampling points was $2,5 \mathrm{~km}$ (Carneiro et al. 2021). The bait traps were placed in the early morning and removed in the afternoon. We carried out the sampling expeditions for three days in the rainy season (November 2019 to March 2020) and two days in the dry season (August to September 2019 and July 2020), totaling 45 hours of sampling effort in each landscape (9 hours day x 5 sampling days). The specimens are deposited in the pollinating insects collection of the Experimental Ecology Sector, Laboratório de Ciências Ambientais, Universidade Estadual do Norte Fluminense - UENF.

We evaluated five variables from the Euglossini bee communities: richness, total abundance, common species abundance, intermediate species abundance, and rare species abundance. The alpha diversity of euglossine communities are measures that show robust responses to forest loss and landscape degradation processes (Cândido et al. 2018; Allen et al. 2019). We combined frequency of occurrence (FO) and species dominance (D) to rank the species into three groups: common species ( $\mathrm{FO} \geq 50 \%$, and $\mathrm{D} \geq 5 \%$ in the community), rare species ( $\mathrm{FO}<$ $25 \%$, and $\mathrm{D}<2.5 \%$ ), and intermediate species (other combinations between occurrence frequency and dominance) (Carneiro et al. 2021).

\subsection{Delimitation and classification of the landscape structure}

We delimited buffers of $1500 \mathrm{~m}$ for the landscape classification from the bee sampling points. The landscapes were mapped by delimiting polygons and visual classification. We used high-resolution satellite images accessed within the ArcGis software as background (Esri, Maxar, GeoEye, Earthstar Geographics, CNES/Airbus DS, USDA, USGS, AeroGRID, IGN, and the GIS User Community). We used 14-class thematic resolution for mapping (Fig. 2) on a scale of 1:2,500, the same as defined in Carneiro et al. (2021). We converted the vectorized maps into raster files (5-m resolution) to analyze the landscape structure. Because we aimed to assess the influence of the landscape composition on larger spatial scales on euglossine bees, we used the rasterized maps (30-m resolution) of the Brazilian Annual Land Use and Land Cover Mapping Project [collection 4.1, 2020] (available at $<$ www.mapbiomas.org $>$ ). From this map, we delimited buffers up to $3000 \mathrm{~m}$ from the bee sampling points.

\subsection{Local and regional multiscale approaches}


We used a multiscale approach in two combined approaches: coupled local and decoupled regional scales. The first approach refers to the usual coupled multiscale approach (Jackson and Fahrig 2015; Miguet et al. 2016), where the landscape structure is measured in nested scales with different spatial extensions from the focal patch where we sampled the biological variables (Brennan et al. 2002; Jackson and Fahrig 2014). In the second approach, landscape structure metrics such as forest cover and heterogeneity are measured using a decoupled part of the larger spatial extent, without using the smaller nested extents (Rhodes et al. 2009; Silveira 2014) (Fig. 3). Then, there are differences in the landscape context between these two multiscale approaches. If the forest cover, for example, is measured in the coupled scales (i.e. nested), the forest cover of a smaller spatial scale (e.g. $500 \mathrm{~m}$ ) influences the forest cover observed on a larger spatial scale (e.g. $1000 \mathrm{~m}$ ). Although there is an increase in spatial extent, the forest cover measured at a larger scale includes the same forest patches of a smaller scale. However, if we measure the forest cover in the decoupled scales, the forest cover on a smaller scale is not aggregated to the forest cover considered on a larger scale. This is because a smaller scale (i.e. $500 \mathrm{~m}$ ) is cut out of the system and quantifies only the forest patches between 500 and $1000 \mathrm{~m}$ (Fig. 3). For these reasons, we considered that the coupled approach represents the local scales, and the decoupled approach disregarding the local landscape attributes, the regional scales (Fig. 3).

The scale decoupling was performed using the "extract by mask" tool in ArcGIS software. We decoupled the following scales: $500-250 \mathrm{~m}$ (i.e. cut the $250 \mathrm{~m}$ scale in the $500 \mathrm{~m}$ scale), 1000 $500 \mathrm{~m}$ (cut the $500 \mathrm{~m}$ scale in the $1000 \mathrm{~m}$ scale), $1500-500 \mathrm{~m}, 2000-1500 \mathrm{~m}$, and $3000-1500 \mathrm{~m}$. We used our raster map (5-m resolution) in the coupled and decoupled multiscale approaches in the spatial extension up to $1500 \mathrm{~m}$. We used the MapBiomas raster map (30-m resolution) only for landscape analysis in the decoupled approach, in the spatial extension between 1500 and $3000 \mathrm{~m}$ (Fig. 3).

\subsection{Landscape metrics}

We calculated two landscape composition metrics. The landscape heterogeneity was measured through the Shannon diversity index (SHDI) (McGarigal 2015). We measured the forest cover (\%) from the Percentage of Landscape (PLAND) index. These metrics were obtained in the $\mathrm{R}$ landscapemetrics package with the $l s m$ function (Hesselbarth et al. 2019). We previously quantified these two landscape metrics in all coupled local scales $(250,500,1000$, and $1500 \mathrm{~m})$ and decoupled regional scales $(500,1000,1500,2000$, and $3000 \mathrm{~m})$. We quantified Pearson's correlation between the landscape metrics in three steps to avoid the correlation between the explanatory variables. First, we correlated the forest cover and landscape heterogeneity between 
local scales (Fig. S1). In the second step, we correlated the forest cover and heterogeneity only between regional scales (Fig. S2). Finally, we correlated the forest cover and landscape heterogeneity between local and regional scales (Fig. S3). In each of these steps, the metrics with high Pearson's correlation $(r>0.65)$ on the same spatial scale or between scales were removed for the subsequent correlation analyses (Rhodes et al. 2009). In the last correlation step, we selected the landscape metrics with Pearson's correlation $r<0.65$ (Fig. S4). Thus, we considered as explanatory variables: (a) forest cover $(500 \mathrm{~m})$ and landscape heterogeneity $(1000 \mathrm{~m})$ on local scales (Fig. 3), and (b) forest cover (1000 and $3000 \mathrm{~m}$ ) and landscape heterogeneity (1500, 2000 and $3000 \mathrm{~m}$ ) on regional scales (Fig. 3).

\subsection{Statistical analysis}

First, we used linear models (LMs) to fit models between the response variables and the landscape attributes (forest cover and heterogeneity) in each spatial scale (local: 500 and $1000 \mathrm{~m}$; regional: 1000, 1500, 2000, and $3000 \mathrm{~m}$ ). Since altitude influences these euglossine communities (Carneiro et al. 2021), we also previously analyzed how altitude influences our understanding and the explanatory power of the system. For this, we used the response variable residuals in the LMs analysis. Since abundance data generally requires log-transformation in base 10, we analyzed four LM for each of the abundance variables (i.e. total abundance, abundance of common, intermediate, and rare species): (a) abundance $\sim$ explanatory variables, (b) residual (abundance) $\sim$ explanatory variables, (c) $\log 10$ (abundance) explanatory variables, and (d) residual (log10(abundance)) explanatory variables. We chose the response variable based on the gain or loss of explanatory power $\left(R^{2}\right)$ of the variables in each of these LMs scenarios. We also considered the association strength $\left(R^{2}\right)$ between response variables and altitude (Table S1, S2 and S3). Based on these criteria, we used the response variables: richness, residual of $\log 10$ (total abundance), residual of $\log 10$ (common species abundance), $\log 10$ (intermediate species abundance), and $\log 10$ (rare species abundance) (Table S1, S2 and S3).

After these exploratory steps, we chose the LMs with $R^{2}>0.1$ for analyses through Generalized Linear Models - GLMs. Because species richness is count data, we built GLMs with Poisson distribution for this response variable, and we used the Gaussian distribution for abundance variables. We aimed to understand the ecological responses to the explanatory variables interacting in both local and regional scales. Then, besides univariate GLMs, we used bivariate GLMs combining as explanatory variables the landscape attributes in local and regional scales (Table S5). The null model was also used in the competition between models, which represented the absence of effect. We used Akaike's Information Criterion corrected for small samples (AICc) 
to rank the models (Burnham and Anderson 2002). We considered the most parsimonious model to have the lowest $\triangle \mathrm{AICc}$. Moreover, models with $\triangle \mathrm{AICc}<2.0$ and model weight $(w i)>0.1$ were considered equally plausible for explaining the patterns. All analyses were performed on the R software, and to model selection, we used the ICtab function from the bbmle package (Bolker and R Development Core Team 2020).

\section{Results}

We found four models to explain the Euglossini bee richness. The best model was the null (Table 1). However, other model sets were statistically plausible to explain the euglossine richness $(\triangle \mathrm{AICc}<2.0$ and $w i>0.1)$. The regional landscape heterogeneity $(1500,2000 \mathrm{~m})$ and local forest cover $(500 \mathrm{~m})$ had a positive effect on species richness (Table 1, Fig. 4a, 4b). The landscape composition on local scales had a high explanatory power on residual total abundance. The model with a positive effect of local forest cover $(500 \mathrm{~m})$ and the model that combined a positive effect of local heterogeneity $(1000 \mathrm{~m})$ and a negative effect of the local forest cover $(500 \mathrm{~m})$ best explained the residual total abundance (Table 1, Fig. 4c, 4d).

The landscape composition on local scales had a higher explanatory power on the euglossine abundance. The models of regional scales also explained the species abundance. The forest cover on local $(500 \mathrm{~m})$ and regional $(1000 \mathrm{~m})$ scales positively explained the residual common species abundance (Table 1, Fig. 5a, 5b). The model of forest cover on local scale $(500 \mathrm{~m})$ best explained the intermediate species abundance through a positive relationship (Table 1, Fig. 5c). Another three models were also statistically plausible to explain these species' abundance. These models included a combination of the positive effect of the regional forest cover $(3000 \mathrm{~m})$ with a negative effect of the local forest cover $(500 \mathrm{~m})$ (Table 1, Fig. $5 \mathrm{~d})$, the model with the positive effect of regional forest cover $(3000 \mathrm{~m})$, and the null model (Table 1). The model presenting a positive effect of local landscape heterogeneity $(1000 \mathrm{~m})$ best explained the rare species abundance (Table 1, Fig. 5e). The second plausible model combined the positive effect of regional forest cover (3000 $\mathrm{m})$ and the negative effect of local heterogeneity $(1000 \mathrm{~m})$ (Fig. 5f). The other plausible model to explain the rare species abundance combined a positive effect on regional heterogeneity $(2000 \mathrm{~m})$ and a negative effect on local heterogeneity $(1000 \mathrm{~m})$. Finally, this euglossine species abundance responded negatively to the regional forest cover $(3000 \mathrm{~m})$.

\section{Discussion}


We showed the different ecological responses of Euglossini bees to the landscape composition combining coupled and decoupled multiscale approaches. Overall, the results corroborated most of our hypotheses and expectations. The forest cover had a high explanatory power on a local scale. This landscape attribute positively influenced the total abundance, abundance of common and intermediate species. Furthermore, the landscape heterogeneity had a high explanatory power on both local and regional scales. There was a higher euglossine richness and rare species abundance when the landscape heterogeneity was high in regional and local scales, respectively. Our results highlight that the scale of effect of landscape composition on euglossine species abundance was in local scales. The scale of effect for species richness tends to be regional scale, but this result is inconclusive because of the higher explanatory power of the null model.

\subsection{Landscape context on a local scale explains the Euglossini species abundance}

The importance of forest cover and landscape heterogeneity for bees have been reported (Boscolo et al. 2017; Cândido et al. 2018; Opedal et al. 2020) mainly on small spatial scales (Steffan-Dewenter 2002; Basu et al. 2016). Forest environments provide nesting sites and floral resources (e.g. nectar and pollen) for Euglossini species (Roubik and Hanson 2004; Rocha-Filho et al. 2012). These bees can also benefit from other covers (e.g. pasture and crops) of the compositional heterogeneity (Aguiar et al. 2015; Carneiro et al. 2021). Our results corroborated those findings because they presented a positive influence of forest cover and landscape heterogeneity for the euglossine species abundance.

The total abundance, abundance of common and intermediate species were positively correlated to local forest cover (i.e. $500 \mathrm{~m}$ ). On the other hand, the rare species abundance was positively related to local landscape heterogeneity on a larger spatial scale (i.e. $1000 \mathrm{~m}$ ). Despite the forest cover had a significant contribution to the abundance of several species in the community, such as common and dominant species (e.g. Eulaema nigrita L., Euglossa cordata (L.)), the spatial context is an important predictor for rare species abundance (Basu et al. 2016; Arroyo-Rodríguez et al. 2016). The rare species group represented the highest species richness in the euglossine communities evaluated (Carneiro et al. 2021). However, since we measured these landscape attributes on coupled scales, it is important to consider that the patterns and ecological processes predicted on the larger local scale may be related to those found on the smaller scale (Allen and Starr 1982; Allen and Hoekstra 1991; Gestich et al. 2018). Thus, if the forest cover on a local scale (e.g. $500 \mathrm{~m}$ ) is not accompanied by a high adjacent spatial heterogeneity (e.g. $1000 \mathrm{~m}$ ), the bees dispersion in the landscape can be affected because individuals are in forest patches 
surrounded by low quality environments (Boscolo et al. 2017; Machado et al. 2020). The importance of heterogeneity in the spatial context is supported by the second model explaining total abundance. The landscapes with high heterogeneity on a $1000 \mathrm{~m}$ scale positively influence the total abundance, even when the forest cover on a smaller scale (i.e. $500 \mathrm{~m}$ ) was low.

\subsection{Landscape context on a regional scale explains Euglossini species richness}

Despite the low statistical support through the high explanatory power of the null model, we observed a significant positive influence of regional heterogeneity on species richness. The landscape structure that we analyzed has been altered by different land uses. It resulted in mosaics of forest patches scattered in agricultural areas with different management systems (e.g. agroforestry, coffee crops, managed and unmanaged pastures) (Carneiro et al. 2021). Landscape compositional heterogeneity can positively influence the responses of biodiversity in fragmented ecosystems, particularly euglossine bees. Landscapes with higher land cover diversity can provide complementary resources or habitats essential to organism life cycles (Dunning et al. 1992; Fahrig et al. 2011; Boscolo et al. 2017). The positive response of euglossine species richness on regional scales supports predicting that more complex and heterogeneous landscapes have more species (Fahrig et al. 2011; Tscharntke et al. 2012). In addition, the spatial heterogeneity in regional scales represents the cover and environment diversity used for euglossine species in a spatial extension outside the forest patch context where the bees were sampled.

\subsection{Local and regional scales interacting to explain the Euglossini community}

The local scale of effect for the Euglossini species abundance may be due to different biotic factors on small spatial and temporal scales (e.g. natality, floral resources availability, or parasitism) interacting with abiotic factors distributed in the space (e.g. nesting substrates) (Miguet et al. 2016; Galán-Acedo et al. 2018; Stuber and Fontaine 2019). Moreover, the species abundance is a consequence of the population dynamics such as immigration and emigration on larger spatiotemporal scales (Miguet et al. 2016). This issue was elucidated when we observed that forest cover on a regional scale (i.e. $3000 \mathrm{~m}$ ) also positively influenced the abundance of common, intermediate, and rare species. The euglossine bees have high flight capacity and can keep the same routes to obtain resources in the landscape, a.k.a. trapline behavior (Ackerman et al. 1989; Whikelski et al. 2010). Thus, we consider that the conservation of forest cover (\%) on regional scales might be essential for maintaining foraging habitats and population dynamics (e.g. source/sink) in these fragmented landscapes. In contrast, the association of euglossine richness with landscape heterogeneity on regional scales may be related to population events on larger spatial-temporal scales, such as colonization (Miguet et al. 2016). From the general context of our 
results, it seems plausible to say that Euglossini bee responses depend on the interaction between forest cover and landscape heterogeneity in different spatial scales. These pollinators can benefit when landscape areas of high forest cover are interspersed with areas of high spatial heterogeneity associated with cover types that can be friendly to bees (e.g. unmanaged pastures, agroforestry) (Boscolo et al. 2017; Opedal et al. 2020; Machado et al. 2020; Carneiro et al. 2021).

\section{Final remarks}

Euglossini communities responded well to both forest cover and spatial heterogeneity in different spatial scales. We confirmed the importance of assessing multiscale interactions to understand the patterns and processes in the landscape. To our knowledge, this was the first time that a study combined these multiscale approaches (coupled and decoupled scales) to understand ecological responses to the landscape context. We encourage new studies comparing how the landscape composition and configuration metrics behave when measuring the landscape structure using local and regional scales independently or even combined. These multiscale approaches can help researchers find more solid answers about the influence of landscape structure and human disturbances on biodiversity in different ecosystems.

In addition, we showed the importance of the spatial context surrounding the forest patches for biodiversity parameters through the scale decoupling. Our results indicate that the conservationist concern about local patches without considering the surrounding areas may not be enough to maintain organism populations that depend on forest patches, although species present high mobility potential in the landscape. Because we observed the importance of incorporating regional level landscapes when assessing biodiversity and ecological processes, we can extrapolate the discussion toward the importance of buffer zones associated with conservation units. These areas are essential to minimize the adverse effects of human pressures on biodiversity on the neighborhoods of conservation units. In Brazil, for example, the conservation of buffer zones is still endorsed by environmental laws (e.g. Law $\mathrm{N}^{\circ} 9.985 / 2000$ ).

Finally, we highlight the importance of maintaining forest cover in different landscape spatial extensions for Euglossini bees within agroecosystem-dominated regions at the Atlantic Forest biodiversity hotspot. We also emphasize that the spatial context around these forest patches must be kept heterogeneous through low intensity in land use practices (e.g. agroforestry, unmanaged pasture), providing more friendly landscapes for these pollinators. 


\section{Declarations}

\section{Funding}

398 We thank the CNPq/MCTIC/IBAMA/A.B.E.L.H.A. for financial support (project 400614/2018-9).

399 LSC and CFP thank FAPERJ for the scholarship. LSC and WFS thank CAPES for the scholarship 400 (processes 88887.339454/2019-00; 88882.314552/2019-01). MCG thanks CNPq (process 401 303894/2018-0) and FAPERJ (process 203.321/2017) for their financial support. MCR thanks 402 FAPESP (processes 2013/50421-2; 2020/01779-5), CNPq (processes 312045/2013-1; 403 312292/2016-3; 442147/2020-1) and PROCAD/CAPES (project 88881.068425/2014-01) for their 404 financial support.

405 Conflicts of interest

406 Not applicable.

407 Ethics approval

408 The authorization for collect biological material was provided by Instituto Brasileiro do Meio 409 Ambiente e dos Recursos Naturais Renováveis-IBAMA ( ${ }^{\circ}$ 71013-3).

410 Consent to participate

411 Not applicable.

412 Consent for publication

413 Not applicable.

414 Availability of data and material

415 Additional data is available in supplementary material.

416 Code availability

417 Not applicable.

418 Authors' contributions

419 MCG, LSC, and WMA idealized the study design. MCR delimited the multiscale approaches. LSC 420 and MCR idealized the main hypotheses and quantified the landscape metrics. LSC, MCR, and 421 WFS analyzed the data. CFP and LSC did the spatial analysis. All authors contributed to the 422 manuscript revision. 


\section{References}

Ackerman JD (1989) Geographic and seasonal variation in fragrance choices and preferences of male Euglossine bees. Biotropica 21(4): 340-347

Aguiar WM, Sofia SH, Melo GA, Gaglianone MC (2015) Changes in orchid bee communities across forest-agroecosystem boundaries in Brazilian Atlantic forest landscapes. Environ Entomol 44(6): 1465-1471. https://doi.org/10.1093/ee/nvv130

Allen TFH, Hoekstra TW (1991) Role of heterogeneity in scaling of ecological systems under analysis. In: Kolasa J, Pickett STA (eds) Ecological Heterogeneity. Springer, New York, pp 47-68 Allen TFH, Starr TB (1982) Hierarchy Perspective for Ecological Complexity. University of Chicago Press, Chicago

Allen L, Reeve R, Nousek-McGregor A, Villacampa J, MacLeod R (2019) Are orchid bees useful indicators of the impacts of human disturbance? Ecol Indic 103: 745-755. https://doi.org/10.1016/ j.ecolind.2019.02.046

Amiot C, Santos CC, Arvor D, Bellón B, Fritz H, Harmange C, Holland JD, Melo I, Metzger JP, Renaud PC, Roque FO, Souza FL, Pays O (2021) The scale of effect depends on operational definition of forest cover-evidence from terrestrial mammals of the Brazilian savanna. Landsc Ecol 36(4): 973-987. https://doi.org/10.1007/s10980-021-01196-9

Arroyo-Rodríguez V, Rojas C, Saldaña-Vázquez RA, Stoner KE (2016) Landscape composition is more important than landscape configuration for phyllostomid bat assemblages in a fragmented biodiversity hotspot. Biol Conserv 198: 84-92. https://doi.org/10.1016/j.biocon.2016.03.026 Basu P, Parui AK, Chatterjee S, Dutta A, Chakraborty P, Roberts S, Smith B (2016) Scale dependent drivers of wild bee diversity in tropical heterogeneous agricultural landscapes. Ecol Evol 6(19): 6983-6992. https://doi.org/10.1002/ece3.2360

Ben Bolker and R Development Core Team (2020) bbmle: Tools for General Maximum Likelihood Estimation. R package version 1.0.23.1. https://CRAN.R-project.org/package=bbmle

4 Boscolo D, Metzger JP (2009) Is bird incidence in Atlantic forest fragments influenced by 55 landscape patterns at multiple scales? Landsc Ecol 24(7): 907-918. https://doi.org/10.1007/s10980-009-9370-8

Boscolo D, Tokumoto PM, Ferreira PA, Ribeiro JW, Santos JS (2017) Positive responses of flower visiting bees to landscape heterogeneity depend on functional connectivity levels. Perspect Ecol Conserv 15(1): 18-24. https://doi.org/10.1016/j.pecon.2017.03.002 
460

461

462

463

Brennan JM, Bender DJ, Contreras TA, Fahrig L (2002) Focal patch landscape studies for wildlife management: Optimizing sampling effort across scales. In: Liu J, Taylor WW (eds) Integrating Landscape Ecology into Natural Resource Management. Cambridge University Press, pp 68-91 Brosi BJ (2009) The effects of forest fragmentation on euglossine bee communities (Hymenoptera: Apidae: Euglossini). Biol Conserv 142(2): 414-423. https://doi.org/10.1016/j.biocon.2008.11.003 Burnham KP, Anderson DR (2002) Model selection and multimodel inference: A practical information-theoretic approach. Springer, New York

Carneiro LS, Aguiar WM, Priante CF, Ribeiro MC, Frantine-Silva W, Gaglianone MC (2021) The interplay between thematic resolution, forest cover, and heterogeneity for explaining Euglossini bees community in an agricultural landscape. Front Ecol Evol 9: https://doi.org/10.3389/fevo.2021.628319

Cândido MEMB, Morato EF, Storck-Tonon D, Miranda PN, Vieira LJS (2018) Effects of fragments and landscape characteristics on the orchid bee richness (Apidae: Euglossini) in an urban matrix, southwestern Amazonia. J Insect Conserv 22(3-4): 475-486. https://doi.org/10.1007/ $\underline{\mathrm{s} 10841-018-0075-7}$

Collevatti RG, Santos JS, Rosa FF, Amaral TS, Chaves LJ, Ribeiro MC (2020) Multi-Scale Landscape Influences on Genetic Diversity and Adaptive Traits in a Neotropical Savanna Tree. Front Genet 11:259. https://doi.org/10.3389/fgene.2020.00259

Cushman SA, Landguth EL (2010) Scale dependent inference in landscape genetics. Landsc Ecol 25(6): 967-979. https://doi.org/10.1007/s10980-010-9467-0

Dressler RL (1982) Biology of the orchid bees (Euglossini). Annu Rev Ecol Evol Syst 13(1): 373394

Dunning JB, Danielson BJ, Pulliam, HR (1992) Ecological processes that affect populations in complex landscapes. Oikos 65(1): 169. https://doi.org/10.2307/3544901

Fahrig L (2017) Ecological responses to habitat fragmentation per se. Annu Rev Ecol Evol S 48(1): 1-23. https://doi.org/10.1146/annurev-ecolsys-110316-022612

Fahrig L, Baudry J, Brotons L, Burel FG, Crist TO, Fuller RJ, Sirami C, Siriwardena GM, Martin JL (2011) Functional landscape heterogeneity and animal biodiversity in agricultural landscapes. Ecol Lett 14(2): 101-112. https://doi.org/10.1111/j.1461-0248.2010.01559.x

Franceschinelli EV, Elias MAS, Bergamini LL, Silva-Neto CM, Sujii ER (2017) Influence of landscape context on the abundance of native bee pollinators in tomato crops in Central Brazil. $\mathrm{J}$ Insect Conserv: 21(4): 715-726. https://doi.org/10.1007/s10841-017-0015-y 
Frantine-Silva W, Augusto SC, Tosta THA, Pacheco AS, Kotelok-Diniz T, Apolinário CS, Sofia SH (2021) Genetic diversity and population structure of orchid bees from the Brazilian savanna. J Apic Res 60(3): 385-395. https://doi.org/10.1080/00218839.2021.1898788 Freiria GA, Ruim JB, Souza RF, Sofia SH (2011) Population structure and genetic diversity of the orchid bee Eufriesea violacea (Hymenoptera, Apidae, Euglossini) from Atlantic Forest remnants in southern and southeastern Brazil. Apidologie 43(4): 392-402. https://doi.org/10.1007/s13592-

$498 \quad \underline{011-0104-y}$

499 Fundação SOS Mata Atlântica, INPE (2021) Atlas dos remanescentes florestais da Mata Atlântica:

500

501

502

503

504 período 2019/2020, relatório técnico. Fundação SOS Mata Atlântica, São Paulo

Galán-Acedo C, Arroyo-Rodríguez V, Cudney-Valenzuela SJ, Fahrig L (2019) A global assessment of primate responses to landscape structure. Biol Rev 94(5): 1605-1618. https://doi.org/doi:10.1111/brv.12517

Gestich CC, Arroyo-Rodríguez V, Ribeiro MC, Cunha RGT, Setz EZF (2018) Unraveling the scales of effect of landscape structure on primate species richness and density of titi monkeys (Callicebus nigrifrons). Ecol Res 34(1): 150-159. https://doi.org/10.1111/1440-1703.1009

Haddad NM, Brudvig LA, Clobert J, Davies KF, Gonzalez A, Holt RD, Lovejoy TE, Sexton JO, Austin MP, Collins CD, Cook WM, Damschen EI, et al. (2015) Habitat fragmentation and its lasting impact on Earth's ecosystems. Sc Adv 1(2): e1500052. https://doi.org/10.1126/sciadv.1500052

Hesselbarth MHK, Sciaini M, With KA, Wiegand K, Nowosad J (2019) landscapemetrics: an open-source $R$ tool to calculate landscape metrics. Ecography 42(10): 1648-1657. https://doi.org/10.1111/ecog.04617

Holland JD, Bert DG, Fahrig L (2004) Determining the spatial scale of species' response to habitat. Bioscience 54(3): 227-233. https://doi.org/10.1641/0006-3568(2004)054[0227:dtssos]2.0.co;2 Jackson HB, Fahrig L (2012) What size is a biologically relevant landscape? Landsc Ecol 27(7): 929-941. https://doi.org/10.1007/s10980-012-9757-9

Jackson ND, Fahrig L (2014) Landscape context affects genetic diversity at a much larger spatial extent than population abundance. Ecology 95(4): 871-881. https://doi.org/10.1890/13-0388.1

Jackson HB, Fahrig L (2015) Are ecologists conducting research at the optimal scale? Glob Ecol Biogeogr 24(1): 52-63. https://doi.org/10.1111/geb.12233

Kupfer JA, Malanson GP, Franklin SB (2006) Not seeing the ocean for the islands: the mediating influence of matrix-based processes on forest fragmentation effects. Glob Ecol Biogeogr 15(1): 820. https://doi.org/10.1111/j.1466-822x.2006.00204.x 
525 Levin SA (1992) The problem of pattern and scale in Ecology: The Robert H. MacArthur Award Lecture. Ecology 73(6): 1943-1967

Lyra-Jorge MC, Ribeiro MC, Ciocheti G, Tambosi LR, Pivello VR (2010) Influence of multi-scale landscape structure on the occurrence of carnivorous mammals in a human-modified savanna, Brazil. Eur J Wildl Res 56(3): 359-368. https://doi.org/10.1007/s10344-009-0324-x

Martin AE (2018) The spatial scale of a species' response to the landscape context depends on which biological response you measure. Curr Landsc Ecol Rep 3(1): 23-33. https://doi.org/10.1007/s40823-018-0030-z

Machado T, Viana BF, Silva CI, Boscolo D (2020) How landscape composition affects pollen collection by stingless bees? Landsc Ecol 35(3): 747-759. doi:10.1007/s10980-020-00977-y

McGarigal K (2015) FRAGSTATS help. University of Massachusetts, Amherst

Milne BT (1991) Heterogeneity as a multiscale characteristic of landscapes. In: Kolasa J, Pickett STA (eds) Ecological Heterogeneity. Springer, New York, pp 69-84

Miguet P, Jackson HB, Jackson ND, Martin AE, Fahrig L (2016) What determines the spatial extent of landscape effects on species? Landsc Ecol 31(6): 1177-1194. https://doi.org/10.1007/s10980-015-0314-1

Morante-Filho JC, Arroyo-Rodríguez V, Faria D (2016) Patterns and predictors of $\beta$-diversity in the fragmented Brazilian Atlantic forest: a multiscale analysis of forest specialist and generalist birds. J Anim Ecol 85(1): 240-250. https://doi.org/10.1111/1365-2656.12448

Nagy-Reis MB, Estevo CA, Setz E. ZF, Ribeiro MC, Chiarello AG, Nichols JD (2017) Relative importance of anthropogenic landscape characteristics for Neotropical frugivores at multiple scales. Anim Conserv 20(6): 520-531. https://doi.org/10.1111/acv.12346

Newman EA, Kennedy MC, Falk DA, McKenzie D (2019) Scaling and complexity in Landscape Ecology. Front Ecol Evol 7. https://doi.org/doi:10.3389/fevo.2019.00293

O’Neill RV, Hunsaker CT, Timmins SP, Jackson BL, Jones KB, Riitters KH, Wickham JD (1996) Scale problems in reporting landscape pattern at the regional scale. Landsc Ecol 11(3): 169-180.

Opedal ØH, Martins AA, Marjakangas EL (2020) A database and synthesis of euglossine bee assemblages collected at fragrance baits. Apidologie 51: 519-530. https://doi.org/10.1007/s1359202000739-4

Pokorny T, Loose D, Dyker G, Quezada-Euán JJG, Eltz T (2015) Dispersal ability of male orchid bees and direct evidence for long-range flights. Apidologie 46(2): 224-237. https://doi.org/10.1007/s13592-014-0317-y 
557 Püttker T, Crouzeilles R, Almeida-Gomes M, Schmoeller M, Maurenza D, Alves-Pinto H, Pardini 558 R, Vieira MV, Banks-Leite C, Fonseca CR, Metzger JP, Accacio GM, et al. (2020) Indirect effects of habitat loss via habitat fragmentation: A cross-taxa analysis of forest-dependent species. Biol Conserv 241: 108368. https://doi.org/10.1016/j.biocon.2019.108368

Ribeiro MC, Metzger JP, Martensen AC, Ponzoni FJ, Hirota MM (2009) The Brazilian Atlantic Forest: How much is left, and how is the remaining forest distributed? Implications for conservation. Biol Conserv 142(6): 1141-1153. https://doi.org/10.1016/j.biocon.2009.02.021

Rhodes JR, McAlpine CA, Zuur AF, Smith GM, Ieno EN (2009) GLMM applied on the spatial distribution of koalas in a fragmented landscape. In: Zuur AF, Ieno EN, Walker NJ, Saveliev AA, Smith GM (eds) Mixed Effects Models and Extensions in Ecology with R. Springer, Stanford University, pp 469-492

Rocha-Filho LC, Krug C, Silva CI, Garófalo CA (2012) Floral resources used by Euglossini bees (Hymenoptera: Apidae) in coastal ecosystems of the Atlantic Forest. Psyche: 1-13. https://doi.org/ $\underline{10.1155 / 2012 / 934951}$

Roubik DW, Hanson PE (2004) Orchids bees of tropical America: biology and field guide. INBio Press, Heredia

Rossi JP, van Halder I (2010) Towards indicators of butterfly biodiversity based on a multiscale landscape description. Ecol Indic 10(2): 452-458. https://doi.org/10.1016/j.ecolind.2009.07.016 Silveira GC (2014) Estrutura de comunidades de abelhas Euglossina (Hymenoptera; Apidae) e análise da distribuição em Florestas Estacionais Semideciduais e em paisagens fragmentadas no Sudeste do Brasil. Dissertation, Universidade Estadual do Norte Fluminense

Steffan-Dewenter I (2002) Landscape context affects trap-nesting bees, wasps, and their natural enemies. Ecol Entomol 27(5): 631-637. https://doi.org/10.1046/j.1365-2311.2002.00437.x

Stuber EF, Fontaine JJ (2019) How characteristic is the species characteristic selection scale? Glob Ecol Biogeogr 28(12): 1839-1854. doi:10.1111/geb.12998

Tscharntke T, Tylianakis JM, Rand TA, Didham RK, Fahrig L, Batáry P, Bengtsson J, Clough Y, Crist TO, Dormann CF, Ewers RM, Fründ J, et al. (2012) Landscape moderation of biodiversity patterns and processes - eight hypotheses. Biol Rev 87(3): 661-685. https://doi.org/10.1111/j.1469-185x.2011.00216.x

Turner MG (1989) Landscape Ecology: The effect of pattern on process. Annu Rev Ecol Evol Syst 20(1): 171-197. doi:10.1146/annurev.es.20.110189.001131

Turner MG, Gardner RH (2015) Landscape Ecology in Theory and Practice. Springer, New York Wiens JA (mcrisgag@uenf.br 1989) Spatial Scaling in Ecology. Funct Ecol 3(4): 385 
590

591

592

593

594

$595 \mathrm{Wu}$ J (2007) Scale and scaling: a cross-disciplinary perspective. In: Wu J, Hobbs RJ Key Topics in

596 Landscape Ecology. Cambridge University Press, Cambridge, pp 15-142

Wikelski M, Moxley J, Eaton-Mordas A, López-Uribe MM, Holland R, Moskowitz D, Roubik DW, Kays R (2010) Large-range movements of neotropical orchid bees observed via radio telemetry. PLoS One 5(5): e10738. https://doi.org/10.1371/journal.pone.0010738

Wu J (2004) Effects of changing scale on landscape pattern analysis: scaling relations. Landsc Ecol 19(2): 125-138. https://doi.org/0.1023/b:land.0000021711.40074.ae
597

598

599

600

601

602

603

604

605

606

607

608

609

610

611

612

613

614

615

616

617

618

619

620

621

622

614

621

7

8

600

601

2

3

5

607

909

1

12

613

20


623 Table 1 The most parsimonious Generalized Linear Models ( $\triangle \mathrm{AICc}<2.0$ and $w i>0.1)$ to explain

\begin{tabular}{|c|c|c|c|c|}
\hline Response variable & Models & $\Delta \mathrm{AICc}$ & df & weight (wi) \\
\hline \multirow[t]{4}{*}{ Richness } & Null & 0.0 & 1 & 0.26 \\
\hline & Regional heterogeneity (2000 m) & 0.97 & 2 & 0.15 \\
\hline & Regional heterogeneity $(1500 \mathrm{~m})$ & 1.12 & 2 & 0.14 \\
\hline & Local forest cover $(500 \mathrm{~m})$ & 1.65 & 2 & $-\underline{0.11}$ \\
\hline Residual Total & Local forest cover $(500 \mathrm{~m})$ & $\overline{0} . \overline{0}$ & 3 & $0 . \overline{49}$ \\
\hline Abundance $(\log 10)$ & $\begin{array}{l}\text { Local forest cover }(500 \mathrm{~m})+\text { Local } \\
\text { heterogeneity }(1000 \mathrm{~m})\end{array}$ & 1.81 & 4 & 0.20 \\
\hline Residual Common & Local forest cover $(500 \mathrm{~m})$ & $\overline{0} \overline{0}$ & 3 & $0 . \overline{38}$ \\
\hline $\begin{array}{l}\text { Species Abundance } \\
---(\log 10)-\ldots\end{array}$ & Regional forest cover $(1000 \mathrm{~m})$ & 1.79 & 3 & 0.15 \\
\hline Intermediate & Local forest cover $(500 \mathrm{~m})$ & $\overline{0} \overline{0}$ & 3 & 0.32 \\
\hline \multirow[t]{3}{*}{$\begin{array}{l}\text { Species Abundance } \\
(\log 10)\end{array}$} & $\begin{array}{l}\text { Local forest cover }(500 \mathrm{~m})+\text { Regional } \\
\text { forest cover }(3000 \mathrm{~m})\end{array}$ & 0.09 & 4 & 0.31 \\
\hline & Regional forest cover $(3000 \mathrm{~m})$ & 1.03 & 3 & 0.19 \\
\hline & Null & 1.44 & 2 & $\underline{0.15}$ \\
\hline Rare Species & 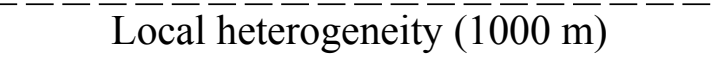 & $\overline{0} . \overline{0}$ & 3 & $0 . \overline{21}$ \\
\hline \multirow[t]{3}{*}{ Abundance $(\log 10)$} & $\begin{array}{l}\text { Local heterogeneity }(1000 \mathrm{~m})+\text { Regional } \\
\text { forest cover }(3000 \mathrm{~m})\end{array}$ & 0.55 & 4 & 0.16 \\
\hline & $\begin{array}{c}\text { Local heterogeneity }(1000 \mathrm{~m})+\text { Regional } \\
\text { heterogeneity }(2000 \mathrm{~m})\end{array}$ & 0.75 & 4 & 0.14 \\
\hline & Regional forest cover $(3000 \mathrm{~m})$ & 1.42 & 4 & 0.10 \\
\hline
\end{tabular}
the five attributes of the Euglossini bee community (richness, residual total abundance, residual common species abundance, intermediate species abundance, and rare species abundance). The forest cover (\%) and landscape heterogeneity were the explanatory variables on local and regional scales 


\section{Figure captions}

642 Fig. 1 Expectations contributions and patterns for the relationship of Euglossini community and landscape attributes: (a) expected contribution of each independent variable (forest cover - FOR;

644 and landscape heterogeneity - HET) on the explanatory power of the models at local (lower L) and 645 regional (lower R) scales; (b) expected relationship between ecological responses and landscape 646 attributes at local and regional scales, warmer colors refers to more positive ecological responses; 647 (c-f) predictions of the Euglossini community responses to landscape composition on local scales 648 and regional scales

649 Fig. 2 Location and land use composition of the 15 landscapes in Southeast Brazil with sampling 650 points of Euglossini bees

651 Fig. 3 Multiscale landscape in coupled and decoupled approaches used to quantify the landscape 652 composition. The black dashed line refers to the $500 \mathrm{~m}$ scale in coupled local scales and decoupled 653 regional scales, while the red dashed line refers to the $1500 \mathrm{~m}$ scale decoupled at the regional 654 scales

655 Fig. 4 Relationship between richness (a-b) and residual total abundance (c-d) of Euglossini species 656 with forest cover (\%) and landscape heterogeneity at local (L.) and regional (R.) scales. The black 657 line is the GLM fit, and the gray shadow the 95\% confidence interval

658 Fig. 5 Relationship between residual common species abundance (a-b), abundance of intermediate 659 (c-d) and rare species (e-f) with forest cover (\%), and landscape heterogeneity quantified on local 660 (L.) and regional (R.) scales. The black line represents the GLM fit, while the gray shadow is the $66195 \%$ confidence interval 
(a)

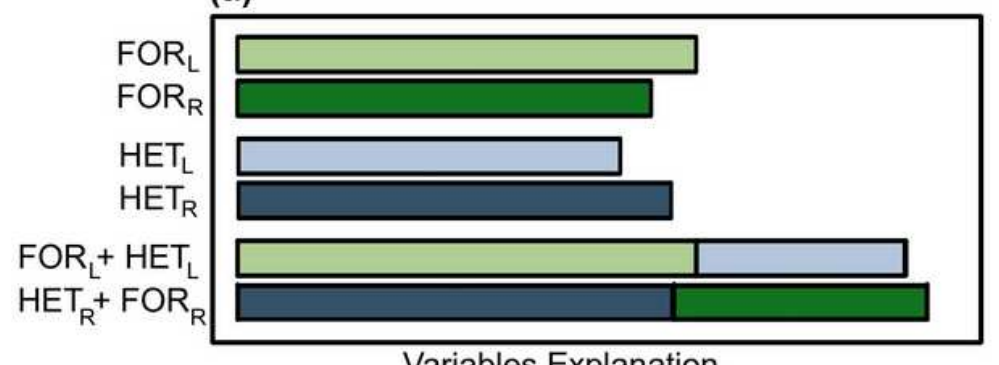

Variables Explanation

(c)

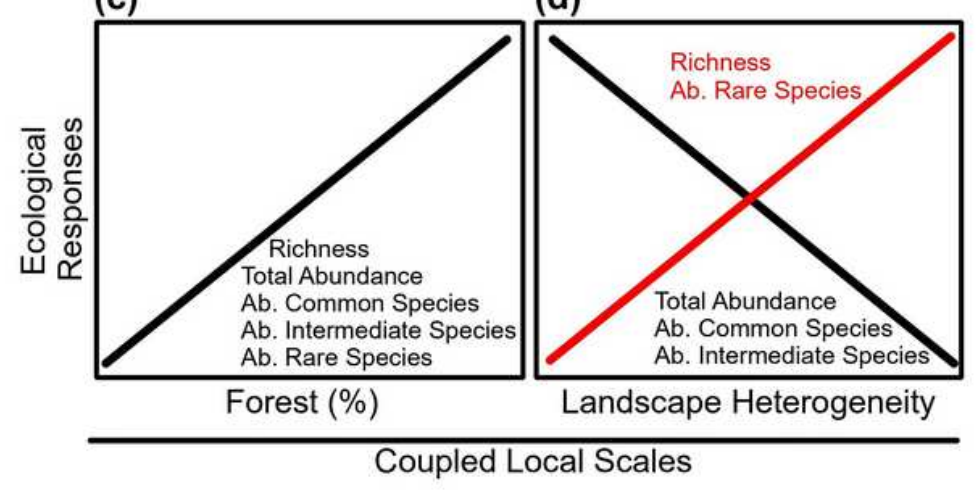

(b)

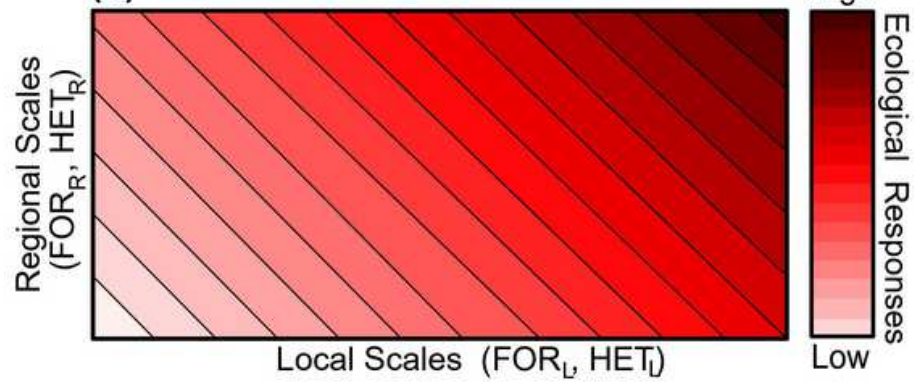

(e)

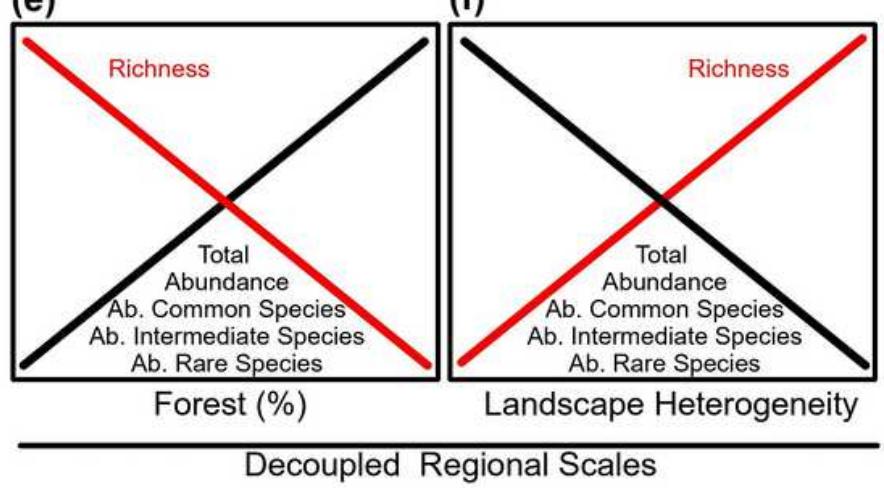

Figure 1

Expectations contributions and patterns for the relationship of Euglossini community and landscape attributes: (a) expected contribution of each independent variable (forest cover - FOR; and landscape heterogeneity - HET) on the explanatory power of the models at local (lower $\mathrm{L}$ ) and regional (lower R) scales; (b) expected relationship between ecological responses and landscape attributes at local and regional scales, warmer colors refers to more positive ecological responses; (c-f) predictions of the Euglossini community responses to landscape composition on local scales and regional scales 

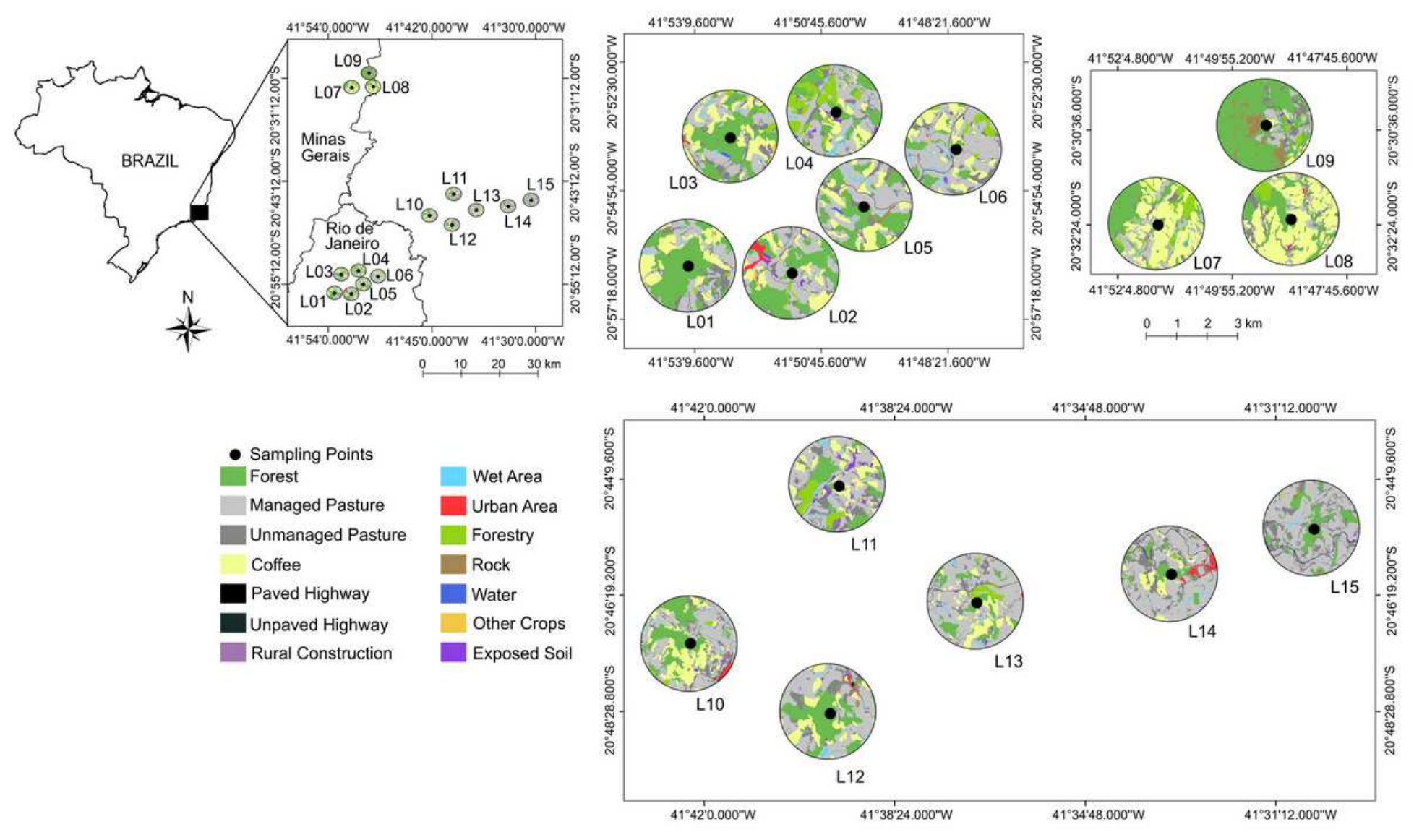

\section{Figure 2}

Location and land use composition of the 15 landscapes in Southeast Brazil with sampling points of Euglossini bees 


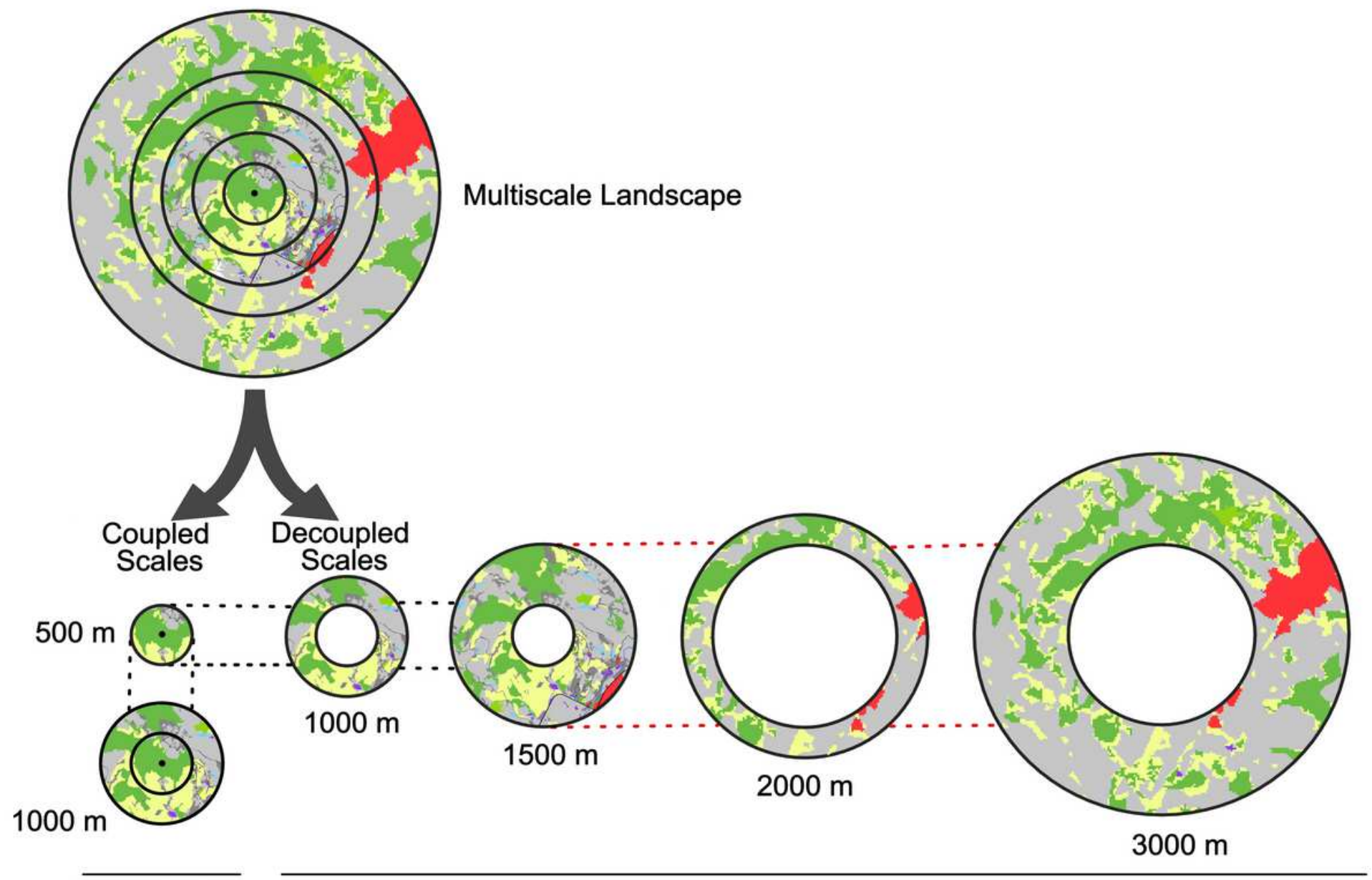

$\overline{\text { Local Scales }}$

Regional Scales

Figure 3

Multiscale landscape in coupled and decoupled approaches used to quantify the landscape composition. The black dashed line refers to the $500 \mathrm{~m}$ scale in coupled local scales and decoupled regional scales, while the red dashed line refers to the $1500 \mathrm{~m}$ scale decoupled at the regional scales 
(a)

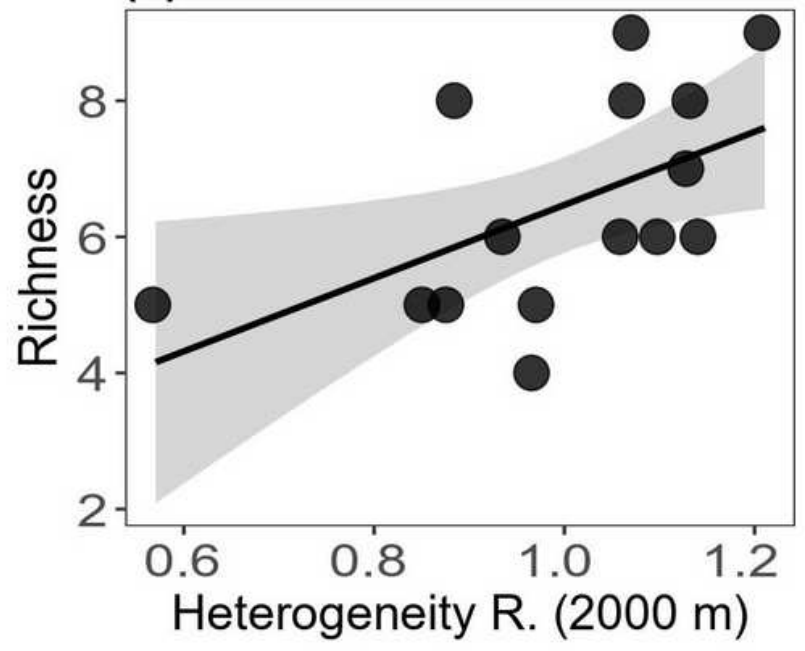

(c)

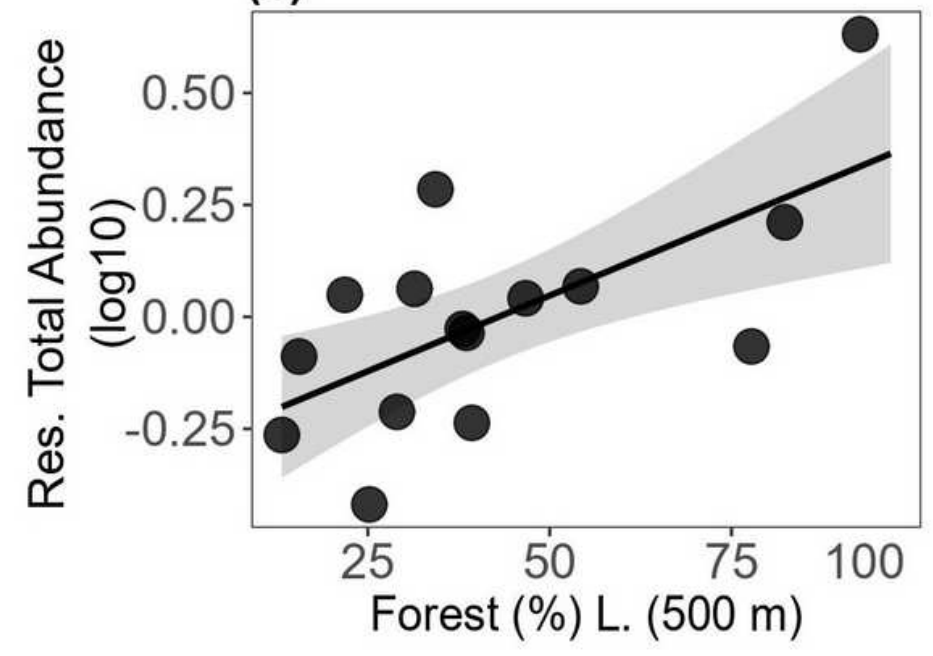

(b)

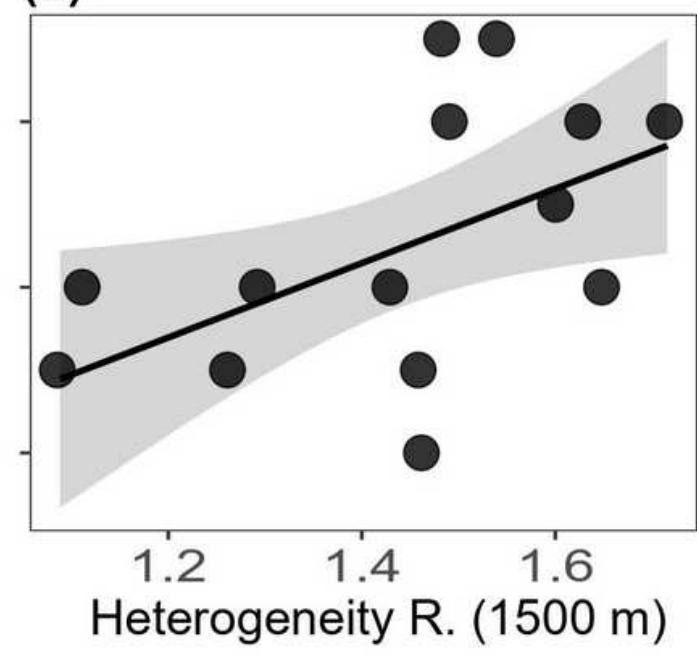

(d)

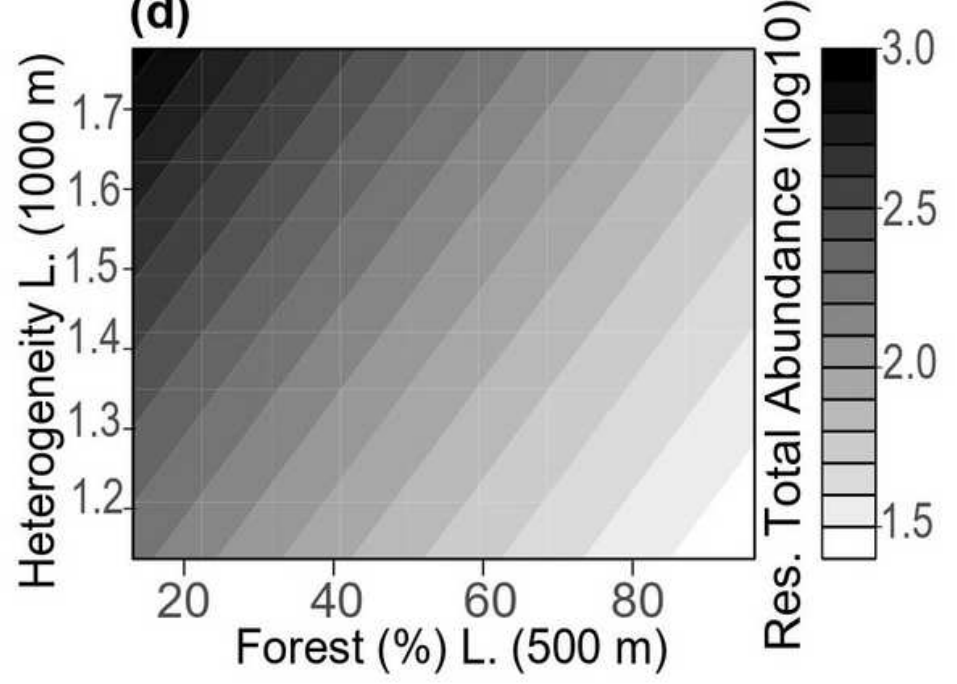

Figure 4

Relationship between richness (a-b) and residual total abundance (c-d) of Euglossini species with forest cover (\%) and landscape heterogeneity at local (L.) and regional (R.) scales. The black line is the GLM fit, and the gray shadow the $95 \%$ confidence interval 


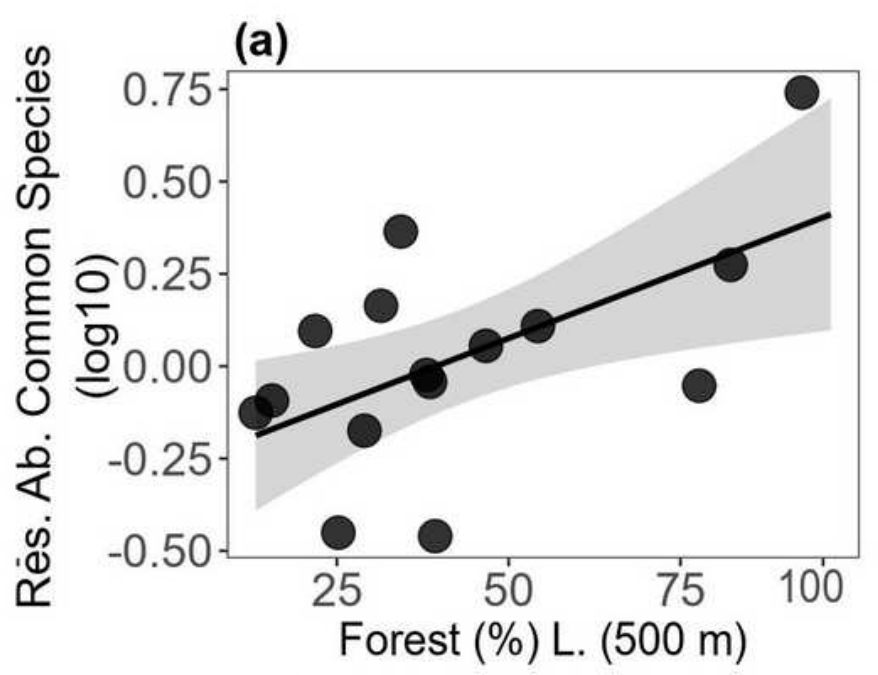

(c)

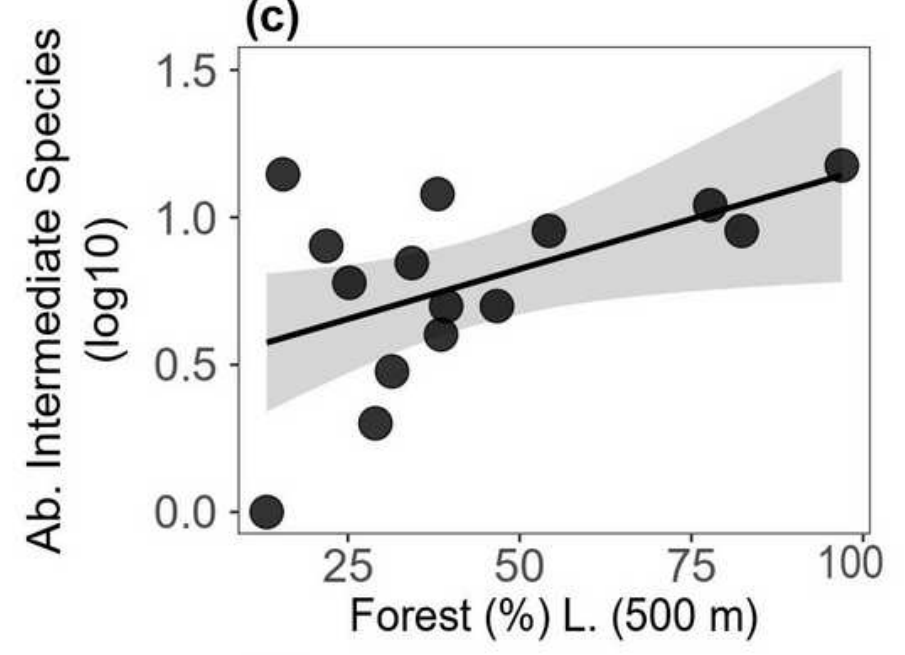

(e)

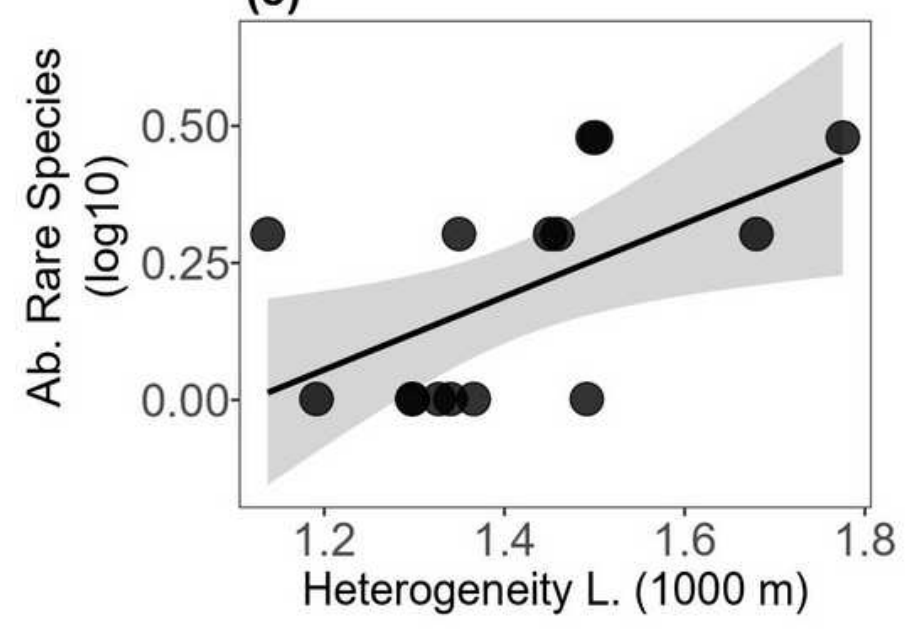

(b)

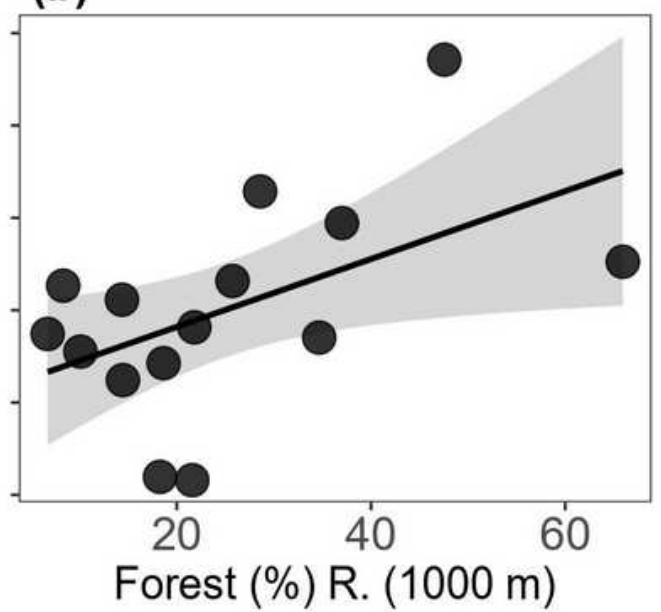

(d)
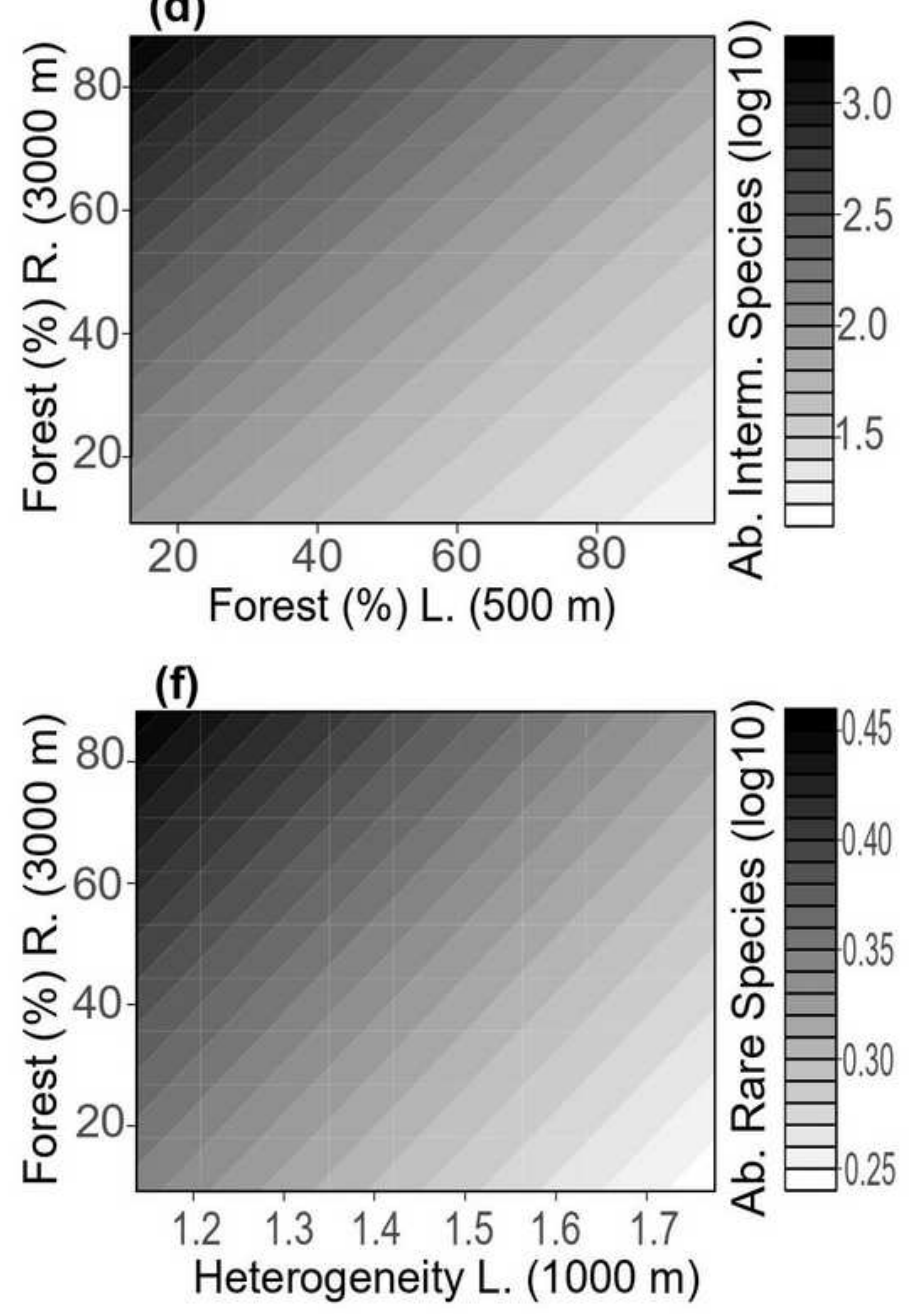

\section{Figure 5}

Relationship between residual common species abundance (a-b), abundance of intermediate (c-d) and rare species (e-f) with forest cover (\%), and landscape heterogeneity quantified on local (L.) and regional (R.) scales. The black line represents the GLM fit, while the gray shadow is the $95 \%$ confidence interval

\section{Supplementary Files}


This is a list of supplementary files associated with this preprint. Click to download.

- SupplementaryMaterial.docx 